\title{
Erratum to: Anthropomorphism as a conservation tool
}

\author{
Alvin A. Y.-H. Chan
}

Published online: 4 September 2012

(c) Springer Science+Business Media B.V. 2012

\section{Erratum to: Biodivers Conserv (2012) 21:1889-1892 DOI 10.1007/s10531-012-0274-6}

The author wishes to add the following footnote to his paper:

"While I thought of the idea independently, I now see there have been at least two previous discussions of using anthropomorphism to accomplish conservation goals. The first is Adcroft (2011), who discusses using anthropomorphism in film to inspire conservation action. Another is a paper discussed during a recent AAG Annual Meeting that found zoo visitors are less concerned about conserving species with fewer similarities and suggests anthropomorphism can be useful for conservation (Smith et al. 2012)."

\section{References}

Adcroft J (2011) Reframing perceptions of anthropomorphism in wildlife film and documentary. Dissertation, University of Otago

Smith AM, Smith L, Weiler B (2012) The potential for an anthropomorphized flagship species to promote concern and community participation in wildlife conservation. In: AAG Annual Meeting, New York

The online version of the original article can be found under doi:10.1007/s10531-012-0274-6.

\footnotetext{
A. A. Y.-H. Chan ( $ه)$

Department of Ecology and Evolutionary Biology, University of California, 621 Young Drive South, Los Angeles, CA 90095-1606, USA

e-mail: cyh@ucla.edu
} 